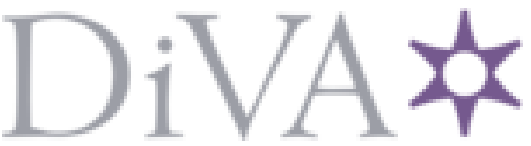

http://www.diva-portal.org

Preprint

This is the submitted version of a paper presented at 2018 XIII International Conference on Electrical Machines (ICEM).

Citation for the original published paper:

Bitsi, K., Kowal, D., Moghaddam, R-R. (2018)

3-D FEM Investigation of Eddy Current Losses in Rotor Lamination Steel Sheets

In:

https://doi.org/10.1109/ICELMACH.2018.8507048

N.B. When citing this work, cite the original published paper.

Permanent link to this version:

http://urn.kb.se/resolve?urn=urn:nbn:se:kth:diva-237413 


\title{
3-D FEM Investigation of Eddy Current Losses in Rotor Lamination Steel Sheets
}

\author{
Konstantina Bitsi, Damian Kowal, and Reza - Rajabi Moghaddam
}

\begin{abstract}
In this paper, a test setup that emulates field conditions equivalent to the ones of the rotor of a Salient Pole Synchronous Machine (SPSM) is presented. A 3-D Finite Element Method (FEM) model of the test setup is used to examine the induced eddy currents and to estimate losses using direct eddy current calculation method. The high mesh resolution of the model enables an accurate calculation and detailed illustration of the induced eddy currents as well as the estimation of related losses via direct computation within the volume of the test samples. A comparison of the estimated eddy current losses is made for different lamination thicknesses and materials of the test object. In the paper it is shown that the approximation that the eddy current losses are directly proportional to the square of the lamination thickness is not valid in the considered cases.
\end{abstract}

Index Terms-Eddy currents, Eddy current losses, Measurement setup, Traveling wave, Air-gap harmonics, 2-D FEM simulations, Rotor losses, Skin effect, Salient-Pole Synchronous Machine.

\section{INTRODUCTION}

Nowadays, a general trend in the design process of electrical machines is to limit the costly and time consuming physical prototyping. Instead, virtual prototyping is used to design and optimize machines. Virtual designs, based on analytical and numerical models, are used by engineers to simulate the operation of electrical machines and to predict their overall performance. The widely used numerical technique for electromagnetic design of electrical machines is the Finite Element Method (FEM).

For the estimation of the core losses, various iron loss models have been introduced and are available in FEM software products. Nonetheless, an accurate prediction of these losses is still challenging. In many cases, the losses are calculated through post-processing computation of the magnetic field and separation into classical eddy current losses, hysteresis losses and excess losses based on Bertotti's theory of loss separation [1].

The basic form of this method shows several inadequacies. Usually the estimation takes into account only the fundamental frequency and assumes that the induction waveform has no local minima (minor hysteresis loops). In [2], Lin et al. propose a time-domain core loss model that considers the phenomenon of minor loops and the effect

K. Bitsi is with the School of Electrical Engineering and Computer Science, KTH Royal Institute of Technology, Stockholm, Sweden (e-mail: bitsi@kth.com).

D. Kowal and R. R. Moghaddam are with ABB Corporate Research, Västerås, Sweden (e-mails: damian.kowal@se.abb.com, Reza.R.Moghaddam@se.abb.com) of the harmonics by introducing an equivalent elliptical hysteresis loop. Although this method provides an acceptable accuracy for hysteresis loss in the time domain, it has the same limitations with the rest of the models based on the theory of loss separation concerning the classical eddy current loss term. In particular, this term is derived considering uniform magnetization and homogeneity of the magnetic field distribution [1]. By assuming that the flux has a uniform and unidirectional distribution across the laminated steel, the models disregard the impact of skin effect, which is particularly prominent at high frequencies.

In the study of the rotor core losses in an electrical machine, the accurate estimation of the eddy current loss term is of major importance, as the rotor is exposed to high contents of space and time harmonics. Especially in the case of a Salient Pole Synchronous Machine (SPSM), the waveform of the magnetic flux density in the pole shoe of the rotor has a high DC value, close to the magnetic saturation region, while it has a very small ac variation due to the field of the higher harmonics. Therefore, the domain wall motion caused by this field can be considered insignificant, while the area of the resulting minor hysteresis loop is particularly small. Consecutively, the total hysteresis losses inside the volume of the rotor under these field conditions can be assumed to be negligible compared to the eddy current losses, which become the major core loss component.

For the estimation of eddy current losses in an electrical machine, and especially in the rotor of a SPSM, the technique that is assumed to give the most reliable results is based on 3-D FEM direct loss computation of eddy currents. This method calculates the electric current density $J$ via direct computation by the finite element analysis (FEA) in the transient type of solution, where the solver uses the $T_{v}-\Omega$ formulation [3]. The resistive losses of induced eddy currents inside the volume of the lamination can be directly defined by the following equation:

$$
p_{\text {res }}=\frac{1}{\sigma} \int_{v o l} J^{2} \cdot d V
$$

where $\sigma$ is is the electrical conductivity of the material of the body.

The resultant estimations from the simulations need to be validated through measurements. However, the complexity of the geometry of the rotor of a SPSM (presence of damper windings, slip rings and brushes or brushless exciters etc.) makes it difficult to directly measure iron losses on it. Consequently, the use of a measurement system that is able to emulate the field conditions from the perspective of the 


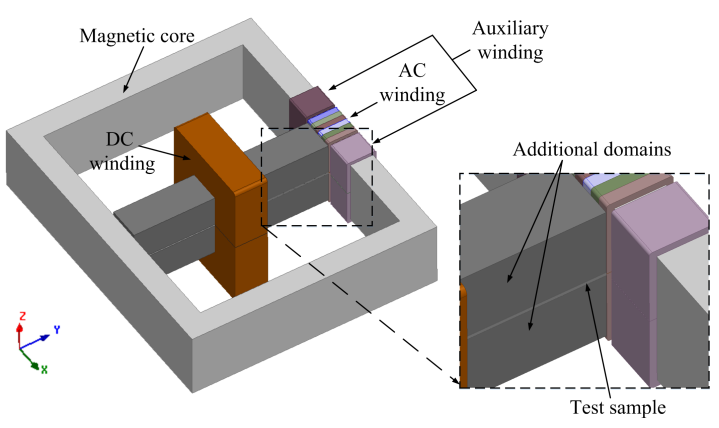

Fig. 1. Geometry of the 3-D design of the measurement setup. Close up of the test sample and the additional domains on the top and bottom of it.

TABLE I

EXCITATION CHARACTERISTICS

\begin{tabular}{l|r}
\hline Effective Frequency, $f(\mathrm{~Hz})$ & 1350 \\
\hline Amplitude of the current in the AC winding (A) & 41.5 \\
\hline Number of turns of the AC winding & 8 \\
\hline Amplitude of the current in the auxiliary winding (A) & 62.25 \\
\hline Number of turns of the auxiliary winding & 8 \\
\hline Value of the current in the DC winding (A) & 32.01 \\
\hline Number of turns in the DC winding & 328 \\
\hline
\end{tabular}

rotor is preferable. As it is explained in [4], none of the existing loss measurement systems have this ability. In [4], the geometry of a measurement setup capable of subjecting test samples to field conditions equivalent to the existent in the rotor of a SPSM is developed in a 2-D FEM model. In order to emulate appropriate magnetic conditions in the setup without any mechanical rotation, the test sample is exposed to a magnetic traveling wave which is created in the airgap $g$ of the setup. This traveling wave is produced only by one frequency, the effective frequency, which substitutes the sum of higher harmonics produced in the air-gap of the actual SPSM due to the interaction of the stator and rotor magnetic fields [4]. In this paper, a 3-D FEM model of this measurement setup is designed and utilized to investigate the eddy current rotor losses in laminated $\mathrm{Si}-\mathrm{Fe}$ steel.

The outline of this paper is as follows: in section II, a detailed description of the 3-D model of the measurement setup is presented, whereas in section III the induced eddy current loops within the volume of the test sample are observed. In section IV, a comparison of the estimated eddy current losses with direct computation is made for different lamination thicknesses. In addition, the influence of the material of the test sample as well as the wavelength of the magnetic traveling wave on the resulting losses is discussed. Conclusions are drawn in the last section.

\section{3-D MODEL DESCRIPTION}

The 3-D geometry of the designed setup with a 2-pole 3 -phase winding and a $2 \mathrm{~mm}$ thick test sample is shown in Fig. 1. The excitation characteristics of the model are listed in Table I. It is comprised of a rectangular magnetic core and an $\mathrm{AC}$ winding wound on it. A test sample made from the same material as the magnetic core (electrical steel of

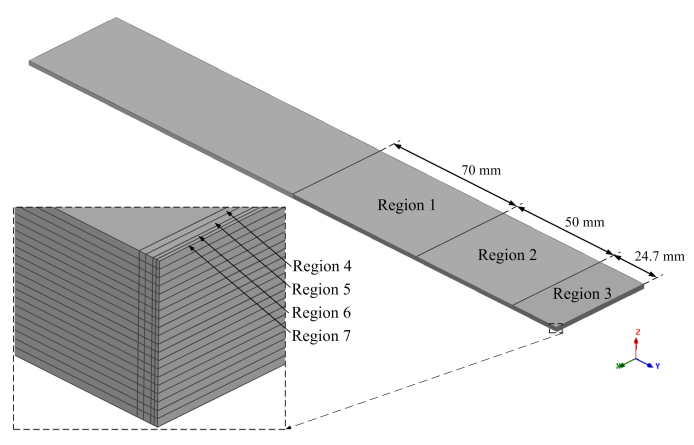

Fig. 2. Regions of the front half of the test sample in the case of $2 \mathrm{~mm}$ lamination thickness.

TABLE II

WIDTHS OF THE REGIONS IN THE FRONT HALF OF THE TEST SAMPLE

\begin{tabular}{c|c|c|c|c|c|c|c}
\hline Region & 1 & 2 & 3 & 4 & 5 & 6 & 7 \\
\hline Width $(\mathrm{mm})$ & 70 & 55 & 24.7 & 0.1 & 0.1 & 0.05 & 0.05 \\
\hline
\end{tabular}

equivalent conductivity and B-H curve with a silicon steel of M400-50A grade) is placed in the center of the geometry with a DC winding on it. In addition, an auxiliary AC excitation is placed on both branches of the magnetic core in order to achieve constant amplitude of the magnetic traveling wave in the air-gap between the test sample and the AC winding [4]. It can be observed that at the top and bottom of the test sample two additional domains are modeled. These domains have the same material assigned as the tested lamination. They are included in the design in order to reduce the end effects of the test setup influencing the field distribution in the middle lamination (test sample).

It was concluded from the investigation in the $2 \mathrm{D}$ model that the main part of the AC flux is concentrated in the front half of the test sample that is closer to the AC excitation [4]. As a result, the analysis of the eddy currents loss is focused only on this area and the generated eddy currents in the rest of the test sample are considered negligible. In order to model with high accuracy, the front half of the test object is divided into thin layers of $0.1 \mathrm{~mm}$ width in the z-direction, see Fig. 2. This length is an approximation of the average skin depth, $\delta$, in the investigated cases, that was calculated in the 2-D model from the estimated $\mathrm{B}(\mathrm{t})$ in the area of the test sample that is closer to the $\mathrm{AC}$ winding. In addition, the test sample is divided into 7 regions in the y-direction, as it is presented in Table II, in order to improve the mesh in the area closer to the AC winding where the eddy currents mainly arise. In Fig. 2, the different regions in which the test object is divided for the case of $2 \mathrm{~mm}$ lamination thickness are shown. It should be noted that Regions 4-7 are not part of Region 3.

In order to determine the appropriate depth of the setup, a sensitivity analysis is conducted in the model with a 2pole AC winding and a $2 \mathrm{~mm}$ thick test sample. A small area in the air-gap between the test object and the $\mathrm{AC}$ winding with depth equal to the thickness of the lamination is defined as air-gap $g$, as shown in Fig. 3. On a line in the middle of the air-gap $g$ between the test object and the AC 


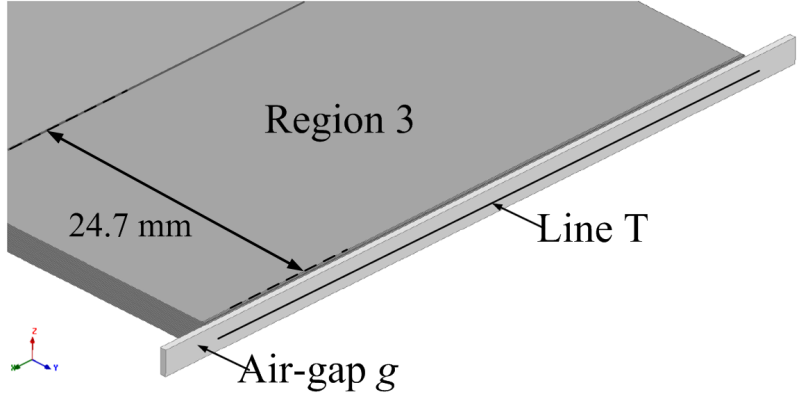

Fig. 3. Close up of the air-gap g.

TABLE III

CHARACTERISTICS OF THE TRAVELING WAVE OF MAGNETIC INDUCTION IN THE MIDDLE OF THE AIR-GAP $g$ FOR THE 2-D MODEL AND DIFFERENT AXIAL LENGTHS OF THE 3-D MODEL

\begin{tabular}{|c|c|c|c|c|c|c|}
\hline Model & 2-D & $3-\mathrm{D}$ & $3-\mathrm{D}$ & $3-\mathrm{D}$ & $3-\mathrm{D}$ & $\begin{array}{l}\text { 3-D with } \\
\text { symmetry } \\
\text { boundaries }\end{array}$ \\
\hline Depth (mm) & 100 & 100 & 200 & 300 & 500 & 100 \\
\hline $\begin{array}{c}\text { Estimated mass } \\
\text { of the active } \\
\text { length }(\mathrm{kg})\end{array}$ & 64.64 & 64.64 & 122.28 & 179.91 & 293.23 & - \\
\hline $\begin{array}{l}\text { DC value of the } \\
\text { magnetic induction } \\
\text { in the middle of the } \\
\text { air-gap } g, B_{D C}(\mathrm{~T})\end{array}$ & 1 & 0.874 & 0.974 & 1.013 & 1.029 & 1.066 \\
\hline $\begin{array}{l}\text { Amplitude of the } \\
\text { AC variation of the } \\
\text { magnetic induction } \\
\text { in the middle of the } \\
\text { air-gap } g, \widehat{B}(\mathrm{~T})\end{array}$ & 0.073 & 0.073 & 0.075 & 0.076 & 0.069 & 0.074 \\
\hline $\begin{array}{c}\text { Maximum value of } \\
\text { the magnitude of } \\
\text { the magnetic field } \\
\text { on the two sides of } \\
\text { the traveling wave, } \\
B_{m}(\mathrm{~T})\end{array}$ & 1.755 & 1.756 & 1.731 & 1.718 & 1.709 & 1.595 \\
\hline
\end{tabular}

winding, the produced traveling wave of magnetic induction $\mathrm{B}(\mathrm{x})$ is recorded for one electrical period $\mathrm{T}=0.74074 \mathrm{~ms}$. As it is shown in Table III, there is a noticeable discrepancy between the results of the 3-D and the 2-D model for the depth of $100 \mathrm{~mm}$ in terms of the DC value of the magnetic induction, $B_{D C}$. This phenomenon is believed to be caused by the end effects in the model and especially due to the leakages at the top and the bottom surfaces of the geometry. In order to justify this claim, two odd symmetry boundaries are imposed on top and on bottom of the setup while the depth of the model is selected to be $100 \mathrm{~mm}$ (Fig. 4). The flux is considered to be entirely tangential on the surfaces that these boundaries are placed and as a result the depth of the model is assumed infinite. The elimination of the end effects in this case is indicated by the smaller deviation of the resulting $B_{D C}$ from the respective value of the 2-D model compared to the previous cases and by the lower value of the flux leakages due to the high concentration of flux in the corners of the test sample, $B_{m}$.

To sum up, it is challenging to specify the optimal depth

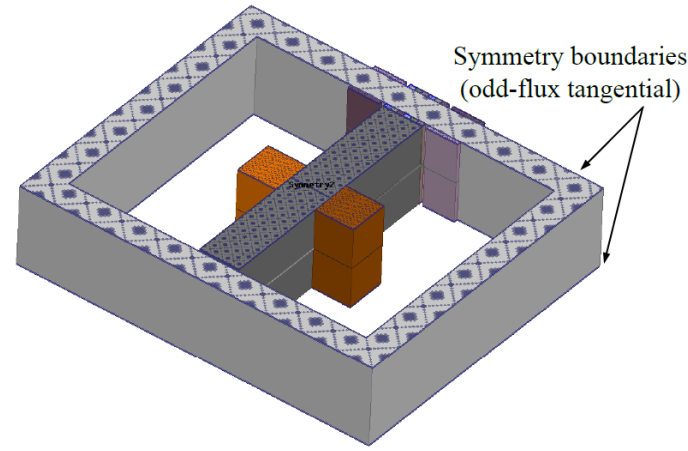

Fig. 4. Symmetry boundaries in the 3D model.

of the 3-D model due to the strong presence of fringing fields that cause magnetic flux leakages. For greater depths (300 mm, $500 \mathrm{~mm}$ ), the resulting magnetic fields produced by the setup can be considered in accordance with the results of the 2-D model (variance $\leq 10 \%$ ). However, the mass of the active material (copper and steel) in these cases exceeds reasonable limits, as shown in Table III. For the further theoretical 3-D investigation in this paper, the idealized model with the symmetry boundaries shown in Fig. 4 will be used.

\section{ANALYSIS OF EDDY CURRENTS IN THE VOLUME OF THE TEST SAMPLE}

In the designed setup, the magnetic field $B$, which is created by the $\mathrm{AC}$ winding, is inducing voltages inside the volume of the test sample. As the material of the test sample is conductive, these voltages result in the creation of eddy currents which flow in closed loops in planes perpendicular to the magnetic field $B$. According to the Maxwell - Faraday equation:

$$
\nabla \times E=-\frac{\partial B}{\partial t}
$$

where $\nabla \times$ is the curl operator and $E$ is the spatially-varying, non-conservative electric field of the eddy currents induced by the time-varying magnetic field $B$ of the AC excitation [5]. If $E$ is defined by the Ohm's Law, the above equation becomes:

$$
\nabla \times J=-\sigma \cdot \frac{\partial B}{\partial t}
$$

Therefore, the magnitude of the eddy currents density is proportional to the rate of change of the magnetic field, $\partial B / \partial t$, and to the conductivity, $\sigma$, of the material of the test sample.

An investigation of these resulting eddy currents is made in the case of the setup with a 2-pole $\mathrm{AC}$ winding and a test sample of $2 \mathrm{~mm}$ lamination thickness and of the material properties equivalent to $\mathrm{SiFe}$ steel grade M40050A. The simulation results are analyzed during the $3^{\text {rd }}$ period $\mathrm{T}(\mathrm{t}=1.48148 \mathrm{~ms}-2.22222 \mathrm{~ms})$, where the initial transients have passed and the eddy current losses have reached steady-state. 


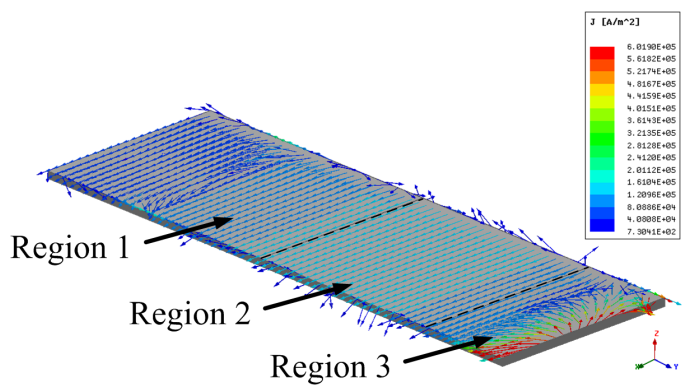

Fig. 5. Induced eddy current density $J$ in Regions 1,2 and 3 on the external face of the top layer of the test sample for the time instant $t=1.48148 \mathrm{~ms}$.

For the time instant $\mathrm{t}=1.48148 \mathrm{~ms}$, the vectors of the eddy currents density $J$ on the external surface of the top layer in Regions 1, 2 and 3 of the test sample are presented in Fig. 5. As it is concluded also in the 2-D investigation of [4], it can be observed that the amplitude of the alternating magnetic field is gradually decreasing towards the middle of the test sample, resulting in a proportional reduction in the magnitude of the eddy currents density.

As a next step, the induced eddy currents in Regions 3, 4, 5, 6 and 7 are examined. In these regions, the majority of the AC flux that is crossing to the test sample through the air-gap is forming closed loops. The resulting eddy currents loops are created in planes parallel to the xz-plane and can be observed in Fig. 6. These loops are shown for 3 time instants, together with their current density on the surfaces of the top and the middle layer as well as on the front surface of the test sample (xy-plane) which faces air-gap $g$. In this figure, the dependence of the eddy currents' magnitude on the time derivative $\partial B / \partial t$ of the magnetic induction $\mathrm{B}(\mathrm{x})$ over a line $\mathrm{T}$ in the middle of the air-gap $g$ can be observed. In addition, the directions of the high-current density loops, which are indicated with black arrows in the top layer of the test sample, are in accordance with the sign of the time derivative. In particular, the eddy currents flow clockwise when the time derivative of the flux density is positive and counterclockwise when the time derivative is negative. Finally, the concentration of the circulating eddy currents is significantly higher on the top surface than in the middle due to the phenomenon of the skin effect that pushes the flux and the currents on the outer layer of the test sample.

\section{LAMINATION THICKNESS, MATERIAL AND WAVELENGTH INFLUENCE ON LOSSES}

Initially, the eddy current losses are examined in the setup with a 2-pole AC winding configuration. For this setup, an eddy currents loss analysis is made for different lamination thicknesses $(2 \mathrm{~mm}$ and $0.5 \mathrm{~mm}$ ) as well as materials (silicon steel of grade M400-50A and construction steel) of the test sample. In addition, a comparison is made in the case of the M400-50A $0.5 \mathrm{~mm}$ thick test sample between the estimated eddy current loss through the direct simulation method and the respective results of a time-domain numerical approach based on Bertotti's theory [2]. Finally, the eddy current losses are estimated in the setup with a 4-pole AC winding configuration in order to investigate the impact of the wavelength of the magnetic traveling wave on the induced eddy current losses in the test sample.

\section{A. Comparison of different lamination thicknesses}

The material properties of a silicon steel grade M400$50 \mathrm{~A}$ are assigned to $2 \mathrm{~mm}$ and $0.5 \mathrm{~mm}$ thick lamination of the test object for the same AC and DC excitations. For these two cases, the DC value, $B_{D C}$, and the amplitude of the AC variation, $\widehat{B}$, of the magnetic traveling wave in the middle of the air-gap $g$ are presented in Table IV, along with the maximum value of the magnitude of the magnetic field on the two sides of the traveling wave, $B_{m}$.

TABLE IV

CHARACTERISTICS OF THE TRAVELING WAVE OF MAGNETIC INDUCTION IN THE MIDDLE OF THE AIR-GAP $g$ FOR DIFFERENT LAMINATION THICKNESSES OF THE MATERIAL M400-50A IN THE SETUP WITH A 2-POLE AC WINDING.

\begin{tabular}{c|c|c|c}
\hline Lamination thickness $(\mathrm{mm})$ & $B_{D C}(\mathrm{~T})$ & $\widehat{B}(\mathrm{~T})$ & $B_{m}(\mathrm{~T})$ \\
\hline 2 & 1.0663 & 0.0743 & 1.5947 \\
\hline 0.5 & 1.0750 & 0.0753 & 1.5985 \\
\hline
\end{tabular}

The method that is used for the eddy current loss estimation is based on the direct calculation of the eddy currents inside the volume of the half test sample. The average value of the losses is calculated at the $3^{\text {rd }}$ period $\mathrm{T}(\mathrm{t}=1.48148-2.22222 \mathrm{~ms})$ of the simulations for the two different lamination thicknesses and the results are presented in Table V.

TABLE V

AVERAGE VALUE OF EDDY CURRENT LOSSES FOR DIFFERENT LAMINATION THICKNESSES OF THE MATERIAL M400-50A IN THE SETUP WITH A 2-POLE AC WINDING.

\begin{tabular}{c|c|c}
\hline \multicolumn{3}{c}{ Direct eddy current simulation method } \\
\hline \multirow{2}{*}{$\begin{array}{c}\text { Lamination } \\
\text { thickness }(\mathrm{mm})\end{array}$} & \multicolumn{2}{|c}{ Average eddy current losses } \\
\cline { 2 - 3 } & $(\mathrm{mW})$ & $(\mathrm{mW} / \mathrm{kg})$ \\
\hline 2 & 55.69 & 482.16 \\
\hline 0.5 & 2.54 & 87.97 \\
\hline
\end{tabular}

In the classical formulation of the eddy current losses the loss value increases with the square of the lamination thickness [2]. It is observed that in the simulated conditions with the direct eddy current calculation the increase of eddy current losses between 0.5 and $2 \mathrm{~mm}$ thick lamination is smaller compared to this basic estimation. Taking into account a complicated structure of the eddy current loops resulting from the traveling wave (see Fig. 6) more investigation is needed to explain the difference in loss increase.

\section{B. Comparison of different estimation methods}

In addition, the iron losses in the test sample are estimated in the case of the $0.5 \mathrm{~mm}$ lamination thickness with a timedomain numerical approach based on the statistical model of loss separation [2]. The core loss coefficients of the material 


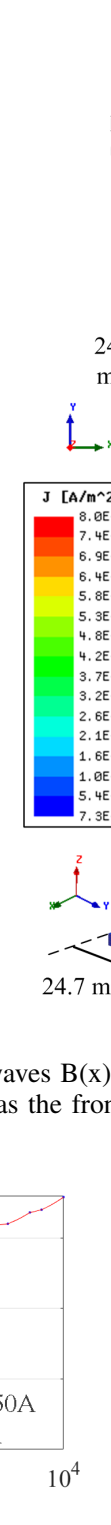

(a)

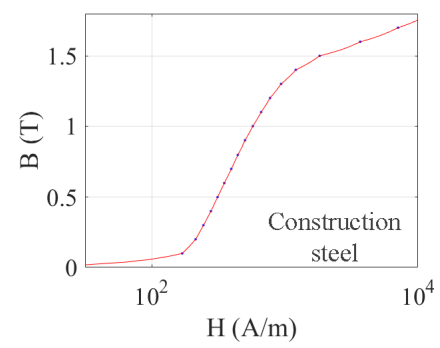

(b)

Fig. 7. Magnetization curves of (a) the electrical steel of grade M400-50A and (b) the construction steel investigated in this study.

where calculated by the FEM software using curve fitting on provided loss measurement data. According to this curve fitting, the excess loss coefficient $\mathrm{k}_{\mathrm{exc}}$ equals to 0 , therefore the calculated core losses comprise of hysteresis and eddy current losses only. The results of this method are compared in Table VI to the respective results of the direct eddy current simulation method.

Comparing the loss calculation results from the statistical core loss model and direct eddy current simulation for $0.5 \mathrm{~mm}$ thick lamination, it can be observed that, the second method gives significantly lower loss value. Such result can be explained by the fact that the skin effect is present for the considered frequency even in $0.5 \mathrm{~mm}$ thick lamination. Presence of the skin effect implies development
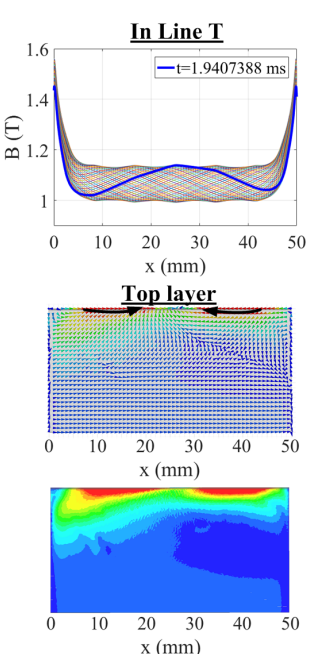

Middle
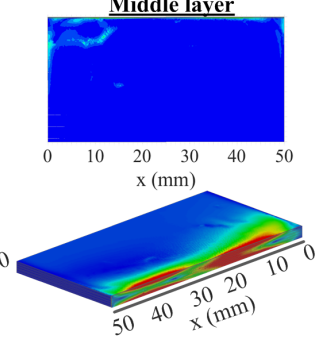

Fig. 6. Magnetic traveling waves $\mathrm{B}(\mathrm{x})$ over the Line $\mathrm{T}$ in the middle of the air-gap g, and magnitude of the eddy current density on the surface of the top and the middle layer as well as the front surface which faces the air-gap $g$ in Regions 3,4,5,6 and 7 of the test sample for 3 different time instants.

TABLE VI

COMPARISON OF THE AVERAGE IRON LOSSES FOR DIFFERENT ESTIMATION METHODS FOR 0.5 MM LAMINATION THICKNESS OF THE MATERIAL M400-50A IN THE SETUP WITH A 2-POLE AC WINDING.

\begin{tabular}{c|c|c|c|c}
\hline \multirow{2}{*}{$\begin{array}{c}\text { Lamination } \\
\text { thickness } \\
(\mathrm{mm})\end{array}$} & $\begin{array}{c}\text { Average } \\
\text { eddy } \\
\text { current } \\
\text { cosses }\end{array}$ & $\begin{array}{c}\text { Average } \\
\text { hysteresis } \\
\text { losses } \\
(\mathrm{mW} / \mathrm{kg})\end{array}$ & $\begin{array}{c}\text { Average } \\
\text { total } \\
\text { core } \\
\text { losses } \\
(\mathrm{mW} / \mathrm{kg})\end{array}$ & $\begin{array}{c}\text { Direct eddy current } \\
\text { simulation method }\end{array}$ \\
\hline 0.5 & 232.38 & 61.3 & 293.68 & $\begin{array}{c}\text { Average } \\
\text { eddy } \\
\text { current } \\
\text { losses } \\
(\mathrm{mW} / \mathrm{kg})\end{array}$ \\
\hline
\end{tabular}

of high density current loops in the material which in turn induce a non-negligible magnetic field that is counteracting the harmonics from the air-gap [6].

\section{Comparison of different materials}

As a next step, a comparison is made in cases where the test sample is made from different materials and has lamination thickness $0.5 \mathrm{~mm}$. Apart from the steel of grade M400$50 \mathrm{~A}$, a construction steel is investigated. The conductivity, $\sigma$ of the two materials as well as the characteristics of the traveling waves of magnetic induction $\mathrm{B}$ in the middle of the air-gap $g$ for the two investigated cases are presented in Table VII. In addition, the magnetization curves of the two materials are shown in Fig. 7.

The average values of the calculated eddy current losses via direct computation (calculated during the 3rd period $\mathrm{T}$ ) 


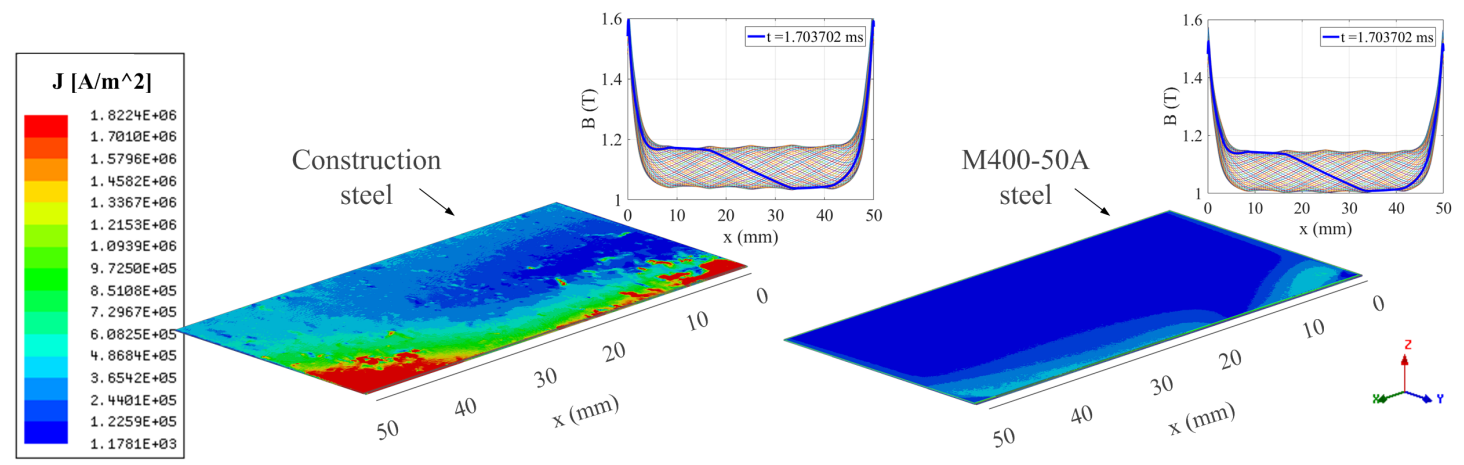

Fig. 8. Eddy current density on the external surface in Regions 3,4,5,6 and 7 of the construction steel and the electrical steel of grade M400-50A for 0.5 mm lamination thickness.

TABLE VII

MATERIAL PROPERTIES AND CHARACTERISTICS OF THE TRAVELING WAVE OF MAGNETIC INDUCTION IN THE MIDDLE OF THE AIR-GAP $g$ FOR DIFFERENT MATERIALS OF THE 0.5 MM THICK TEST SAMPLE IN THE SETUP WITH A 2-POLE AC WINDING.

\begin{tabular}{c|c|c|c|c|}
\hline Material & $\sigma(\mathrm{MS} / \mathrm{m})$ & $B_{D C}(\mathrm{~T})$ & $\widehat{B}(\mathrm{~T})$ & $B_{m}(\mathrm{~T})$ \\
\hline M400-50A & 2.38 & 1.0750 & 0.0753 & 1.5985 \\
\hline construction steel & 7.85 & 1.1072 & 0.0746 & 1.6702 \\
\hline
\end{tabular}

are compared for the two different materials in Table VIII. It can be observed that the eddy current losses in the construction steel are significantly higher compared to the steel M400-50A. A reason for this result is the dependence of the eddy current losses on the conductivity of the material. In addition, the eddy current losses are proportional to the volume within which the eddy currents develop and circulate. This volume depends on the skin depth of each material locally in the different regions of the test object. In Fig. 8, it can be observed that, in the case of the construction material, the circulation of eddy current takes place in a larger part of the volume of the test object due to the deeper flux penetration.

TABLE VIII

AVERAGE VALUE OF EDDY CURRENT LOSSES FOR DIFFERENT MATERIALS OF THE 0.5 MM THICK TEST SAMPLE IN THE SETUP WITH A 2-POLE AC WINDING.

\begin{tabular}{c|c|c}
\hline \multicolumn{3}{c}{ Direct eddy current calculation method } \\
\hline \multirow{2}{*}{$\begin{array}{c}\text { Material of the } \\
\text { test sample }\end{array}$} & \multicolumn{2}{|c}{ Average eddy current losses } \\
\cline { 2 - 3 } & $\mathrm{mW}$ & $(\mathrm{mW} / \mathrm{kg})$ \\
\hline M400-50A & 2.54 & 87.97 \\
\hline construction steel & 7.47 & 253.76 \\
\hline
\end{tabular}

\section{Comparison of different wavelengths}

In addition, the eddy current losses are examined in the case of a 4-pole $\mathrm{AC}$ winding configuration with the same $\mathrm{DC}$ and $\mathrm{AC}$ current excitations as the ones in the model with the 2-pole AC winding (see Table I). The direct eddy current analysis method is utilized for test samples of the material M400-50A with $2 \mathrm{~mm}$ as well as $0.5 \mathrm{~mm}$ lamination thickness. For these two cases, the characteristics of the traveling waves of magnetic induction $\mathrm{B}$ in the middle of the air-gap $g$ are presented in Table IX.

TABLE IX

CHARACTERISTICS OF THE TRAVELING WAVE OF MAGNETIC INDUCTION IN THE MIDDLE OF THE AIR-GAP $g$ FOR DIFFERENT LAMINATION THICKNESSES OF THE MATERIAL M400-50A IN THE SETUP WITH A 4-POLE AC WINDING.

\begin{tabular}{c|c|c|c}
\hline Lamination thickness $(\mathrm{mm})$ & $B_{D C}(\mathrm{~T})$ & $\widehat{B}(\mathrm{~T})$ & $B_{m}(\mathrm{~T})$ \\
\hline 2 & 1.0709 & 0.0710 & 1.6011 \\
\hline 0.5 & 1.0724 & 0.0721 & 1.5911 \\
\hline
\end{tabular}

TABLE X

AVERAGE VALUE OF EDDY CURRENT LOSSES FOR DIFFERENT LAMINATION THICKNESSES OF THE MATERIAL M400-50A IN THE SETUP WITH A 4-POLE AC WINDING.

\begin{tabular}{c|c|c}
\hline \multicolumn{3}{c}{ Direct eddy current simulation method } \\
\hline $\begin{array}{c}\text { Lamination } \\
\text { thickness }(\mathrm{mm})\end{array}$ & \multicolumn{2}{|c}{ Average eddy current losses } \\
\cline { 2 - 3 } & $(\mathrm{mW})$ & $(\mathrm{mW} / \mathrm{kg})$ \\
\hline 2 & 45.42 & 393.25 \\
\hline 0.5 & 1.93 & 66.84 \\
\hline
\end{tabular}

Moreover, the values of the average steady-state eddy current losses during the $3 \mathrm{rd}$ period $\mathrm{T}$ are presented in Table X. The losses in the setup with the 4-pole AC winding are smaller compared to the losses in the setup with the 2-pole $\mathrm{AC}$ winding and the same material $(22.61 \%$ and $24.02 \%$ in the cases of the $2 \mathrm{~mm}$ and the $0.5 \mathrm{~mm}$ respectively - Table $\mathrm{V}$ and Table X). A small deviation can be also noticed in the amplitude of the traveling magnetic waves, $\widehat{B}$, of the two setups $(4.44 \%$ and $4.25 \%$ in the cases of the $2 \mathrm{~mm}$ and the 0.5 $\mathrm{mm}$ respectively, see Table IV and Table IX). This deviation is believed to be caused by a local current saturation around the conductors in the case of the 4-pole AC winding due to the higher current density. As it can be observed in Fig. 9, the number of the eddy current loops in the setup with the 4-pole winding is as expected higher due to the smaller wavelength of the traveling wave and the more frequent changes in the gradient of the waveform.

\section{CONCLUSION}

This paper presents an analysis of the eddy current losses in a measurement setup that subjects the test samples to field 


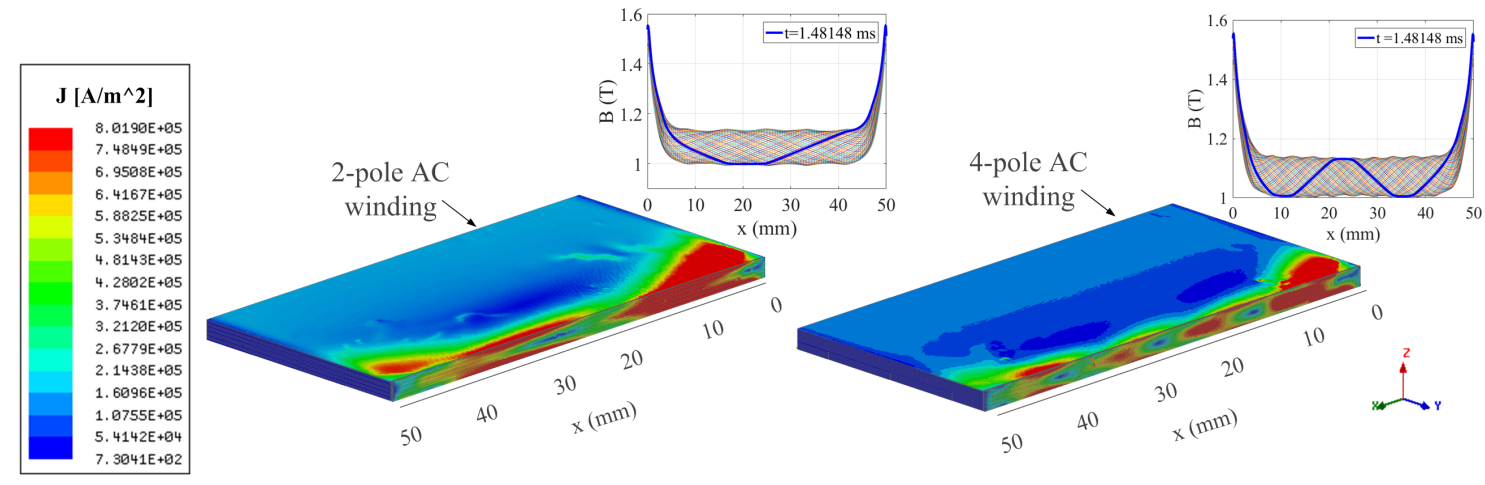

Fig. 9. Magnitude of eddy current density $\mathrm{J}$ in the Regions 3, 4, 5, 6 and 7 of the test sample with 2 mm lamination thickness for both the setups with the 2-pole and 4-pole- AC winding configurations.

conditions equivalent to the existent in the rotor lamination of a SPSM. The 3-D FEM model of this measurement setup is developed to enable the investigation of the assumed three dimensional nature of the studied phenomenon. The direct computation of the eddy current losses by the FEM software within the volume of the test sample for different lamination thicknesses is utilized. The comparison of the results of this method with the incorporated loss model based on the statistical loss separation method (into hysteresis, eddy current and excess losses) shows that the two models have significant discrepancy in the loss estimation. The use of the direct eddy current calculation technique in the investigated cases leads to lower estimated losses, which are not dependent on the square of the lamination thickness. It is claimed that the more reliable results are delivered by the direct eddy current computation method since the statistical loss model is not suited for loss estimation when the skin effect and rotational losses are present. Additionally, due to the skin effect occurring in the lamination the high current density of eddy currents is capable of inducing magnetic field that is opposing the air gap harmonics. This effect is not taken into account when statistical loss model is used.

In addition, the impact of different test materials as well as spatial wavelengths of the magnetic traveling wave on the estimated eddy current losses was investigated. However, in order to give certainty in the simulation results, measurements should be performed on the designed setup. Therefore, within the scope of future work, the experimental validation of the 3-D FEM loss calculations based on direct eddy currents simulations is necessary.

\section{REFERENCES}

[1] G. Bertotti, "General properties of power losses in soft ferromagnetic materials," IEEE Transactions on Magnetics, vol. 24, no. 1, pp. 621630, Jan 1988.

[2] D. Lin, P. Zhou, W. N. Fu, Z. Badics, and Z. J. Cendes, "A dynamic core loss model for soft ferromagnetic and power ferrite materials in transient finite element analysis," IEEE Transactions on Magnetics, vol. 40, no. 2, pp. 1318-1321, March 2004.

[3] (2013) Ansys maxwell magnetic field formulation. [Online]. Available: http://resource.ansys.com/staticassets/ANSYS/staticassets/ resourcelibrary/techbrief/tb-ansys-maxwell-magnetic-field-formulation. pdf
[4] K. Bitsi, D. Kowal, and R. R. Moghaddam, "Novel approach in investigating the rotor lamination iron losses," in 2017 IEEE International Electric Machines and Drives Conference (IEMDC), May 2017, pp. 1-8.

[5] M. Sadiku, Elements of Electromagnetics, 4th ed. Oxford University Press, 2007.

[6] D. Kowal and R. R. Moghaddam, "In depth investigation on the physics based mechanisms of the losses in a single silicon steel sheet used in electrical machines," in 2016 19th International Conference on Electrical Machines and Systems (ICEMS), Nov 2016, pp. 1-6.

\section{BIOGRAPHIES}

Konstantina Bitsi received the M.Sc. degree in electrical and computer engineering from the National Technical University of Athens, Greece, in 2016.

She is currently pursuing the Ph.D. degree in the School of Electrical Engineering and Computer Science, KTH Royal Institute of Technology, Stockholm, Sweden. Her current research interests include electrical machine design and optimization of modular topologies for automotive applications.

Damian Kowal received the M.Sc. degree in electrical engineering from AGH University in Krakow, Poland, in 2008. In 2013 he obtained PhD degree in electromechanical engineering from Ghent University in Ghent, Belgium.

He currently holds a position of senior scientist at ABB Corporate Research Center in Vasteras, Sweden. His research interests include design and optimization of electrical machines.

Reza Rajabi Moghaddam was born in 1974 and received the BSc degree in electrical power engineering from Sharif University of Technology, Tehran, Iran, in 1997 and the MSc and PhD degrees in electrical engineering from the Royal Institute of Technology (KTH), Stockholm, Sweden, in 2007 and 2011, respectively.

During 1997 - 2005, the author worked in different industries in Iran as an electrical engineer in areas such as distribution system (MV and LV) design, lighting design, cubicle construction and design, installation (power plants, GIS-HV substation, etc.), offshore installation, field electrical engineer and consultant.

Since 2006, he has been with ABB Corporate Research, Västerås, Sweden, as a researcher, scientist and technology development project's leader in various areas. His interests include electromechanical energy conversion systems design and optimization, losses in electromechanical energy conversion systems, electromagnetism, installation, and electrical machines and drives with electrical machine design orientation. 